\title{
Motor Cortex Activity Organizes the Developing Rubrospinal System
}

\author{
Preston T.J.A. Williams and John H. Martin \\ Department of Physiology, Pharmacology, and Neuroscience, City College of the City University of New York, New York, New York 10031
}

The corticospinal and rubrospinal systems function in skilled movement control. A key question is how do these systems develop the capacity to coordinate their motor functions and, in turn, if the red nucleus/rubrospinal tract (RN/RST) compensates for developmental corticospinal injury? We used the cat to investigate whether the developing rubrospinal system is shaped by activity-dependent interactions with the developing corticospinal system. We unilaterally inactivated M1 by muscimol microinfusion between postnatal weeks 5 and 7 to examine activity-dependent interactions and whether the RN/RST compensates for corticospinal tract (CST) developmental motor impairments and CST misprojections after M1 inactivation. We examined the RN motor map and RST cervical projections at 7 weeks of age, while the corticospinal system was inactivated, and at 14 weeks, after activity returned. During M1 inactivation, the RN on the same side showed normal RST projections and reduced motor thresholds, suggestive of precocious development. By contrast, the RN on the untreated/active M1 side showed sparse RST projections and an immature motor map. After M1 activity returned later in adolescent cat development, RN on the active M1/CST side continued to show a substantial loss of spinal terminations and an impaired motor map. RN/RST on the inactivated side regressed to a smaller map and fewer axons. Our findings suggest that the developing rubrospinal system is under activity-dependent regulation by the corticospinal system for establishing mature RST connections and RN motor map. The lack of RS compensation on the non-inactivated side can be explained by development of ipsilateral misprojections from the active M1 that outcompete the RST.

Key words: corticospinal tract; development; motor cortex; red nucleus; rubrospinal tract; spinal cord

\section{Significance Statement}

Skilled movements reflect the activity of multiple descending motor systems and their interactions with spinal motor circuits. Currently, there is little insight into whether motor systems interact during development to coordinate their emerging functions and, if so, the mechanisms underlying this process. This study examined activity-dependent interactions between the developing corticospinal and rubrospinal systems, two key systems for skilled limb movements. We show that the developing rubrospinal system competes with the corticospinal system in establishing the red nucleus motor map and rubrospinal tract connections. This is the first demonstration of one motor system steering development, and ultimately function, of another. Knowledge of activitydependent competition between these two systems helps predict the response of the rubrospinal system following corticospinal system developmental injury.

\section{Introduction}

The lateral motor system, comprised of the corticospinal system (CS) and the rubrospinal system (RS), normally functions in the moment-to-moment control of skilled movements (Kuypers, 1981). Motor cortex (M1) and red nucleus (RN) neurons modulate their activity during skilled movements (Cheney et al., 1991; Martin and Ghez, 1991; Fetz et al., 1989;
Lavoie and Drew, 2002; Drew et al., 2004), and their spinal projections, the corticospinal tract (CST) and rubrospinal tract (RST), have overlapping terminations (McCurdy et al., 1987; Williams et al., 2014). Further, during development and in maturity, the RS is thought to compensate for CS injury (Payne and Lomber, 2001; Raineteau and Schwab, 2001; Cahill-Rowley and Rose, 2014).

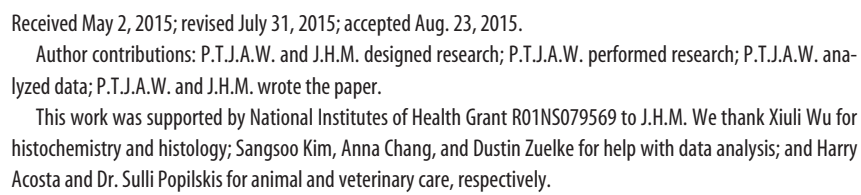

This work was supported by National Institutes of Health Grant R01NS079569 to J.H.M. We thank Xiuli Wu for histochemistry and histology; Sangsoo Kim, Anna Chang, and Dustin Zuelke for help with data analysis; and Harry Acosta and Dr. Sulli Popilskis for animal and veterinary care, respectively.

The authors declare no competing financial interests.

Correspondence should be addressed to Dr. John H. Martin, Department of Physiology, Pharmacology, and Neuroscience, City University of New York School of Medicine, City College of the City University of New York, 160 Convent Avenue, New York, NY 10031. E-mail:jmartin@ccny.cuny.edu. DOI:10.1523/JNEUROSCI.1719-15.2015

Copyright $\odot 2015$ the authors $\quad 0270-6474 / 15 / 3513363-12 \$ 15.00 / 0$ 
A key question is: how do these systems develop the capacity to coordinate their functions? RS development straddles that of the CS: the RN motor map begins developing before and matures later (Williams et al., 2014) than the M1 map (Chakrabarty and Martin, 2000). Development of their spinal projections is also staged, with RST leading CST by several weeks (Williams et al., 2014). This differential timing suggests that RS and CS interact to shape movement development. What might this interplay look like and how can this be studied? Activity-dependent interactions, especially competition, play key roles in development of the CST and motor skills (Martin et al., 2009). Activitydependent competition shapes the contralateral and ipsilateral projections from M1 in each hemisphere. Activity-dependent synaptic competition and/or cooperation may also play roles in codevelopment of CST and primary afferent fiber connections (Gibson et al., 2000; Clowry et al., 2004; Chakrabarty and Martin, 2011a; Chakrabarty and Martin, 2011b). We hypothesize that activity-dependent interactions also play a role in RS and CS codevelopment.

Here we investigated whether the immature RS is shaped by activity-dependent interactions with the developing CS by reversibly inactivating M1, the principal origin of the CST, unilaterally between PW 5 and PW 7 by intracortical microinfusion of the $\mathrm{GABA}_{\mathrm{A}}$ agonist muscimol (Friel and Martin, 2007). During this developmental period, there is loss of transient ipsilateral CST projections and projections into the motor pools (Alisky et al., 1992; Li and Martin, 2000). In cats, PW 7 also is the start of M1 map development (Chakrabarty and Martin, 2000) and when kittens begin expressing skilled movements (Barrett and Bateson, 1978; Martin and Bateson, 1985). For RN, PWs 5-7 is an early period for its motor map development and is when the RST establishes permanent motor pool projections (Williams et al., 2014). Following this inactivation, the CS develops abnormally and movements are impaired. The silenced CST fails to establish strong connections with contralateral spinal motor circuits. The active CST establishes strong contralateral connections and also develops ipsilateral misprojections that overtake the silenced CST (Martin et al., 1999; Chakrabarty and Martin, 2010). When activity of M1/CS returns after cessation of inactivation, both the motor map and movements are impaired permanently unless remediated with interventions (Friel et al., 2014). As development progresses into feline adolescence ( $>$ PW 13), there is further expansion of the ipsilateral CST from the active M1 with concomitant loss of CST projections from the injured side, creating a "vicious circle" (Martin, 2012). Similar changes have been reported in humans after perinatal injury in hemiplegic cerebral palsy (Eyre et al., 2007).

We examined development of the RN motor map and RST projections to the cervical cord at PW 7 while the CS system is inactivated and at PW 14, after CS activity returned and as the animals enter the final stage of adolescent development. We show that the developing RS is under activity-dependent regulation by the CS for establishing the mature RST connections and RN motor map. Surprisingly, we found evidence for RN/RST regression not compensation for CST developmental impairment after inactivation. This regression can be explained by the development of ipsilateral misprojections from the active motor cortex that not only overtake the silenced CST but the RST, in turn, the RN as well.

\section{Materials and Methods}

Subjects. All experimental procedures were approved by and conducted in accordance with the Institutional Animal Care and Use Committee of the City College of the City University of New York. Cats were obtained from an Association for Assessment and Accreditation of Laboratory Animal Care International-accredited supplier and housed in a controlled vivarium with food and water available ad libitum. Cats were delivered in litters of 4 , with a lactating adult female, at least 1 week before the age required for experiments. We used the minimum number of animals necessary to complete the studies and care was taken to reduce any pain or discomfort throughout all experiments. The following animal numbers were used: M1 inactivation PWs 5-7 and terminal experiment PW 7: $n=4$ cats, $n=8$ red nuclei; M1 inactivation PWs 5-7, terminal experiment PW 14: $n=4, n=8$ red nuclei; PW 7 controls: $n=$ $6, n=7$ red nuclei; PW 14 controls: $n=3, n=4$ red nuclei). Control animals were not subjected to intracortical muscimol infusion and were also used in our earlier report (Williams et al., 2014). RST axons and varicosities from controls were analyzed de novo on previously unexamined cervical spinal cord sections. Motor map data from animals with M1 inactivation were compared with age-matched controls from our database of RN motor map parameters (effective sites, site threshold, and joints represented) (Williams et al., 2014). There were no age differences between the groups [PW 7: control (7.76 \pm 0.18$)$; inactivation (7.46 \pm $0.25), t=0.98, p>0.35$; PW 14: control (15.05 \pm 0.70$)$; inactivation $(13.61 \pm 0.41), t=1.90, p>0.11]$. The ages are referred to by the nominal ages of PW 7 and PW 14.

General surgical procedures. Cats were given a broad-spectrum antibiotic (cefazolin, $25 \mathrm{mg} / \mathrm{kg}$ i.m.) for all surgical procedures, and atropine $(0.04 \mathrm{mg} / \mathrm{kg}$ i.m. $)$ was given to reduce oral secretions. Anesthesia was induced with a mixture of acepromazine $(0.03 \mathrm{mg} / \mathrm{kg}$ i.m. $)$ and ketamine hydrochloride $(30 \mathrm{mg} / \mathrm{kg}$ i.m.). Fluids were supplemented with lactated Ringer's solution. All survival surgeries were performed under aseptic conditions, and vital signs were monitored to ensure an appropriate level of anesthesia. For survival surgeries (osmotic pump implantation; tracer injections), animals were intubated and anesthesia maintained with $1.5 \%-3 \%$ isoflurane in oxygen. The head was fixed in a stereotaxic frame and craniotomies made (anteroposterior $0-5 \mathrm{~mm}$; mediolateral $0-4$ $\mathrm{mm}$; depending on age), similar to our previous report (Williams et al., 2014). The depth coordinates were guided by the location of the effects of stimulation of the oculomotor nerve, which travels through or near the ventral RN. Animals were kept in a warming incubator until they recovered from anesthesia and then were returned to their home cage. Kittens typically resumed nursing within $4-6 \mathrm{~h}$ after recovering from anesthesia and were orally supplemented with feline replacement milk (KMR brand) as needed. Immediately following surgery, animals were administered antibiotics (cefazolin $25 \mathrm{mg} / \mathrm{kg}$ i.m.) and analgesics (buprenorphine $0.02 \mathrm{mg} / \mathrm{kg}$ i.m. or carprofen $2 \mathrm{mg} / \mathrm{kg}$ i.m.) twice daily for $2 \mathrm{~d}$ after surgery, or continued if necessary. For terminal experiments (intracortical microstimulation), anesthesia was maintained with continuous infusion of ketamine $(10 \mathrm{mg} / \mathrm{kg} / \mathrm{h}$ i.v.) as in our prior studies (Friel and Martin, 2007).

M1 activity blockade. The $\mathrm{GABA}_{\mathrm{A}}$ agonist muscimol (10 mm in sterile saline; Sigma) was continuously infused using an osmotic minipump (Alzet, model 2002; $0.5 \mu \mathrm{l} / \mathrm{h}$ ) to block neuronal activity. This inactivation method will presumably affect all neurons expressing $\mathrm{GABA}_{\mathrm{A}}$ receptors, including intrinsic neurons and projection neurons to multiple subcortical and cortical targets. The infusion was centered in the M1 forelimb representation, located primarily in the lateral sigmoid gyrus, as in our prior studies (Friel et al., 2012). A 28-gauge hypodermic needle cannula (Alzet), beveled at the tip, was connected with vinyl tubing (Scientific Commodities, size 4) to the pump. The cannula was inserted $1.5 \mathrm{~mm}$ below the pial surface, to the approximate location of pyramidal cell bodies. The cannula was fixed to the skull with screws and dental acrylic cement. Neuronal activity was blocked in M1 from PWs 5-7. Figure $1 A$ shows the timeline for the experiments.

Using the metabolic marker cytochrome oxidase or the level of neuropil immunostaining of the calcium binding protein parvalbumin, this infusion maximally inhibits a $2.5-3 \mathrm{~mm}$ patch of cortex at the infusion site and less inhibition for an additional 4-5 mm (Martin et al., 1999; Friel and Martin, 2007). Based on the distribution of neurofilament-F (SMI-32) immunoreactivity and parvalbumin cell body staining (Martin et al., 1999; Friel et al., 2007), the infusion did not produce a lesion. With 
cessation of the infusion, contact and proprioceptive placing returned within several days suggesting return of activity (Friel et al., 2012).

Rubrospinal axon labeling. Anterograde tracers were injected 2 or 4 weeks before a terminal electrophysiological procedure depending on the age of the animal. We used either $10 \%$ biotinylated dextran amine (BDA; 10,000 MW; Invitrogen) or 10\% AlexaFluor-488 dextran amine (AF488DA; 10,000 MW; Invitrogen), as in our previous study (Williams et al., 2014). For both the present and previous study, we found that these two tracers had similar efficacy in labeling RST axons. The tracer was infused (Picospritzer; World Precision Instruments) using a micropipette over a period of $3-5 \mathrm{~min}$. For each track, we injected $150-300 \mathrm{nl}$ of tracer solution at each of 2 or 3 sites in each track. The total amount of tracer for each RN was 900-1200 nl. Sites were first tested with microstimulation (see below) to locate the forelimb map, and we aimed to label the magnocellular RN preferentially. Injection sites were confirmed postmortem to be located within the RN. An example of tracer injection sites in the left and right $\mathrm{RN}$ in one animal is shown in Figure $1 B$.

Microstimulation motor mapping. We used microstimulation to determine the efficacy of RS projections to evoke forelimb movements at PW 7 or PW 14. For these experiments, we used continuous ketamine infusion intravenously to maintain an areflexive state and muscle tone. Electrode tracks and marking lesions were reconstructed histologically to verify that microstimulation sites were within the red nucleus. As in our previous study, we recorded evoked movements using high-resolution sampling at $200 \mu \mathrm{m}$ depth intervals across multiple anteroposterior and mediolateral origins. We used Paralene-insulated stainless steel microelectrodes (Microprobe; $0.5 \mathrm{~m} \Omega$ nominal impedance, $1-2 \mu \mathrm{m}$ tip) with the following stimulation parameters: $45 \mathrm{~ms}$ duration train, $330 \mathrm{~Hz}, 0.2$ ms biphasic balanced pulses; with a leading cathodal pulse, delivered once every $2 \mathrm{~s}$ using a constant current stimulator (AM Systems). In determining the threshold and topography of microstimulation effects, we kept the limb in a prone posture, typically with the limb stabilized at a proximal joint to verify selective distal joint movement. We characterized movements at the shoulder (retraction, protraction, abduction, adduction), elbow (flexion, extension), wrist (dorsiflexion, plantarflexion, supination, pronation), and at digit joints (dorsiflexion/digit closure, plantarflexion).

We determined the current threshold at effective sites, defined as the lowest current that consistently produced a motor effect. At first, we rapidly raised the current from zero to suprathreshold values, then reduced the current to below threshold, noting the lowest current at which the effect was present. Next, we increased the current and noted when the effect reappeared. We used a maximal current of $125 \mu \mathrm{A}$ to minimize the likelihood of missing effective sites in PW 7 animals and $100 \mu \mathrm{A}$ in PW 14 animals. It has been estimated that $125 \mu \mathrm{A}$ produces current spread of $\sim 375 \mu \mathrm{m}$ in cortex (Asanuma and Sakata, 1967). Small marking lesions were made for histological verification by passing negative direct current (single-pulse, 1-1.5 mA for $10 \mathrm{~s}$ ). These were identified on Nissl-stained section (see Fig. 1C) and with the aid of nearby sections stained for the Prussian blue reaction (see Fig. $1 D, E$ ). Stereotactic coordinates of effective sites were plotted using AutoCAD 2013 for the Macintosh computer (Autodesk). The $z$-axis for reconstructing the forelimb map was referenced across electrode tracks and animals by use of a stereotaxic zeroing stand set to the anatomical center $(-2.5 \mathrm{~mm}$ ventral to interaural plane) of the mature RN (Berman, 1968). The distribution of thresholds obtained for all effective forelimb sites was used for comparisons. Representative electrode tracts and marking lesions are shown in Figure $1 C$.

Histology and tracer histochemistry. Cats were deeply anesthetized (sodium pentobarbital; $30 \mathrm{mg} / \mathrm{kg}$ i.v.) and perfused transcardially with saline (at room temperature), followed by a solution of $4 \%$ PFA at $\mathrm{pH}$ 7.4. Heparin was injected (200-500 U i.v.) at the onset of perfusion. For perfusion, a peristaltic pump was used at a predetermined flow rate that depended on the animal's weight. The total perfusion time was 20-30 min. The brain and spinal cord were removed, postfixed in the same fixative for 2-3 h, and then transferred to $20 \%$ sucrose in $0.1 \mathrm{~m}$ phosphate buffer overnight at $4^{\circ} \mathrm{C}$. Frozen transverse sections $(40 \mu \mathrm{m})$ through the cervical spinal cord (C6-T1) were cut and processed for tracers and markers of interest. Histochemistry for BDA and immunohistochemistry for AF488DA were performed to determine the distribution of labeled
RST terminals and immunohistochemistry for ChAT to determine the distribution of motor pools. Coronal sections through the midbrain were cut and alternate sections were processed for BDA and AF488DA to determine the location of tracer injection sites, Nissl stained for assessing RN cytoarchitecture, and Prussian blue stained for delineating electrode tracks and marking lesions.

For BDA visualization, sections were incubated in PBS containing the avidin-biotin complex reagent as prescribed by the manufacturer (ABC kit; Vector Laboratories) and $0.2 \%$ Triton for $2 \mathrm{~h}$ at room temperature. After rinsing, sections were incubated with the chromogen DAB (Sigma) for 6-30 min. For AF488DA, we used a primary antibody to the tracer (rabbit anti-AlexaFluor-488, 1:400, room temperature, 6-30 min, Invitrogen) and either DAB (secondary; donkey anti-rabbit, 1:200, Vector Laboratories) or fluorescence methods (see below) for visualization. See Figure 1 f for a representative example of BDA labeling of axons and axon varicosities. AF488 axonal staining has a comparable appearance (data not shown).

Topography of RST terminations. We used a quantitative method for determining the topographic distribution of label within the gray matter in the cervical enlargement segments $\mathrm{C} 8-\mathrm{T} 1$ and the regional density of axons and axon varicosities (Brus-Ramer et al., 2007; Friel and Martin, 2007). BDA- and AF488DA-labeled RST axons and associated varicosities were traced from transverse spinal sections at $400 \times$ magnification using Neurolucida (Microbrightfield). Varicosities are defined as punctate axonal swellings with a diameter more than three times the diameter of the nonvaricose axon. Care was taken to verify that axon varicosities were not kinks or other irregularities in the axon. RST axon varicosities are putative presynaptic sites (i.e., boutons) because they colocalize synaptophysin (Williams et al., 2014), as with the CST (Meng et al., 2004; Friel et al., 2012). For each cat, axon label (BDA or AF488DA) in the contralateral gray matter was traced to obtain a representative sample of axon length between 15,000 and $20,000 \mu \mathrm{m}$. Sections of labeled spinal cord were selected from $\mathrm{C} 8$ - $\mathrm{T} 1$ because rubromotoneuronal contacts are present in this region (McCurdy et al., 1987; Williams et al., 2014). Representative RST labeling on a single spinal section and a drawing of combined staining across multiple sections are shown in Figure $1 F, G$.

Tracings of axon label and varicosities were separately exported and quantified further using a suite of programs written in MATLAB (The MathWorks). We applied a correction factor for each animal based on the corresponding number of labeled axons counted in the lateral column (Optical Fractionator probe, StereoInvestigator, MBF) to account for differences in tracer uptake, transport, and histological processing. We constructed color-coded axon and varicosity density maps, corrected for tracer efficacy. Briefly, a program divided the gray matter into $15 \times 15$ $\mu \mathrm{m}$ square regions of interest. For each region, we computed the mean density of traced axons or marked varicosities. All axonal tracings and varicosities were one pixel wide, so axon width or varicosity diameter did not affect density measurements. This corresponds to the amount of label (i.e., total number of pixels) in the region divided by the area of the region. A matrix of mean axon or varicosity density was generated in MATLAB that preserved the mediolateral and dorsoventral dimensions of the distribution of label in the gray matter. At the same time, the borders of the gray matter were traced $(100 \times$ magnification) to obtain a fiducial correspondence between labeling and spinal cord structure. We quantified the regional axon and varicosity density to generate maps of regional distribution of axonal label distribution and to quantify the amount of label in lamina IX (Rexed, 1954). The amount of label in lamina IX was subtracted from the regional amounts to prevent overlap in the datasets for unique comparisons. Density is represented according to a color scale, from the lowest density (blue) to the highest (red). Regional distribution maps were generated for individual animals and averaged maps for all animals within a particular age or treatment group. For the averages, we aligned the data from different animals at the lateral margin of lamina V (Rexed, 1954), where the dorsolateral funiculus forms a wedge-shaped insertion between the gray matter of the dorsal and ventral horns. Further analyses were performed on the axon length and varicosity matrices.

Statistics. We used the program Prism (5.0) for the Macintosh computer to determine the statistical significance of age-related differences. 
We directly compared between active and inactive sides with unpaired $t$ tests. Motor mapping and anatomical data also were compared with age-matched controls, and one-sample $t$ tests were used to test for significance. This permitted us to relate any changes between the two sides within the framework of the typically developing RS. A two-sample KolmogorovSmirnov test was used to compare the cumulative distribution datasets. The graphs plot the mean \pm SEM, unless otherwise specified.

\section{Results}

To determine the role of CS activity in organizing RS development, we inactivated M1 unilaterally between PWs 5-7 in all treated animals (Fig. 1A). In separate animal groups, we examined the developing RS at PW 7, while the M1/CST is inactivated, and at PW 14, after CS activity returned and when development is in the late stages of adolescence. These ages were chosen on the basis of the key stages of CS and RS development (described below). Animals were subjected both to anterograde tracing of the RST and terminal RN motor mapping. We examined the RN motor map on both the same side as the inactivated M1 and on the side of the noninactivated/active motor cortex (Fig. $1 D)$. For the RST, we examined the contralateral projections from the $\mathrm{RN}$ on both sides. We first briefly describe the general effects of M1 inactivation at PWs 5-7. Next, we present the results of mapping studies to determine the effects of CS activity blockade on RN motor representation development, and then RST development.

\section{M1 inactivation}

In all animals, M1 inactivation impaired contralateral paw placing reactions during the PWs 5-7 infusion period, as previously described (Friel and Martin, 2007; Friel et al., 2007). There were no observed impairments in forelimb movements during locomotion on a flat surface or during feeding/social interactions. In 2 of the 4 animals in the PW 14 group, we validated that inactivation between PWs 5-7 resulted in persistent paw placement errors during horizontal ladder walking, which is a characteristic of the prior M1 inactivation (Friel et al., 2007, 2012; Salimi et al., 2008). Analysis of video recordings at PW 12 indicated that the limb contralateral to inactivation overstepped the target during placement of the paw on the rung resulting in an endpoint error (contra-inactivation: $2.35 \pm 0.12 \mathrm{~cm}, n=2$ animals; ipsi-inactivation: $1.59 \pm 0.06 \mathrm{~cm}, n=2$ animals), similar to our previous studies. Previous studies indicated that, after cessation of infusion, limb placing im-

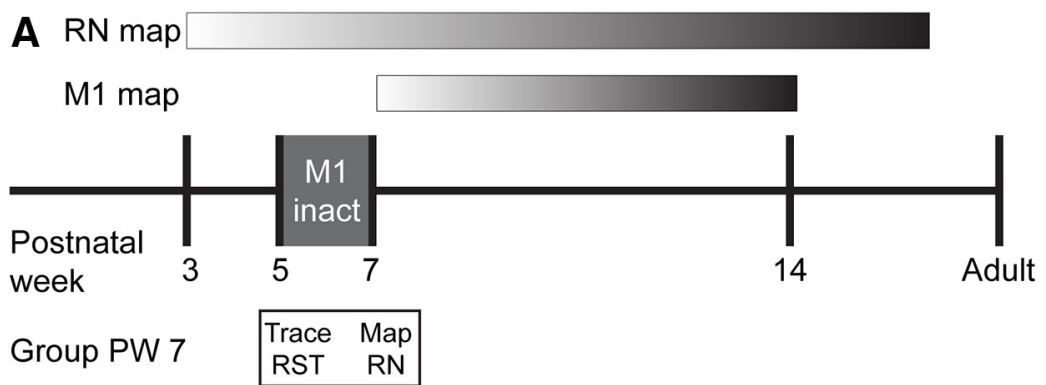

\section{Group PW 14}
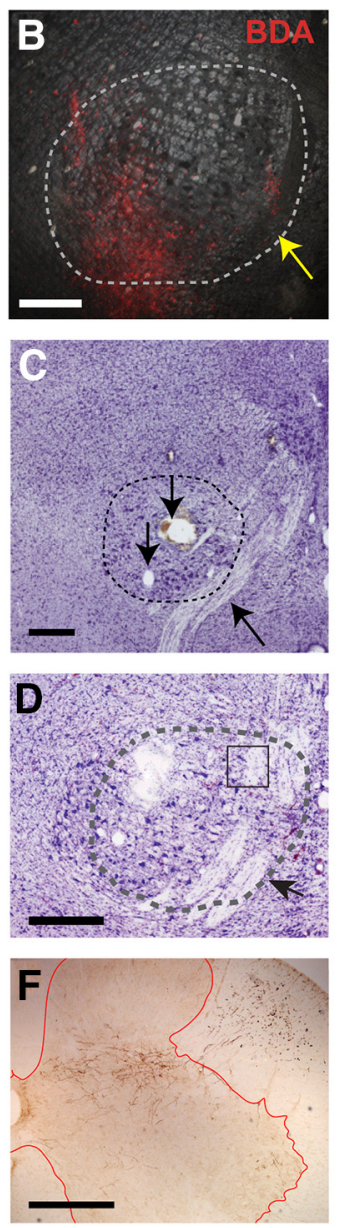

\begin{tabular}{|lc|}
\hline Trace & Map \\
RST & RN \\
\hline
\end{tabular}
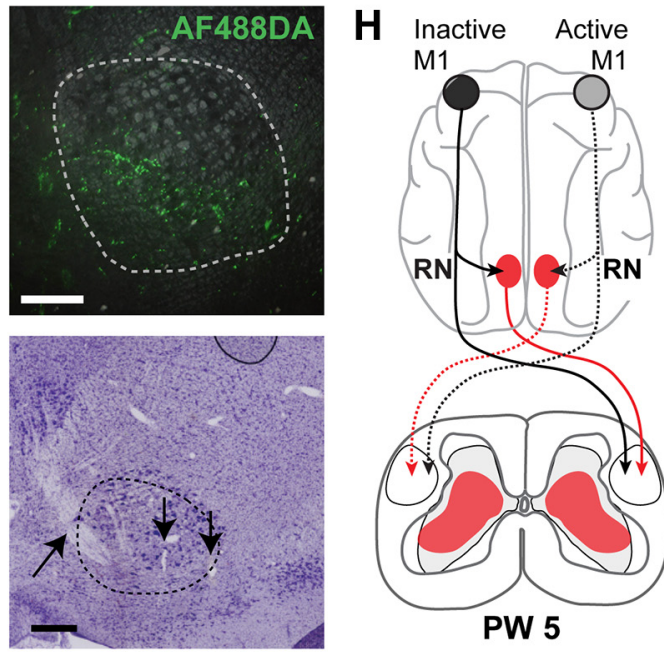

PW 5
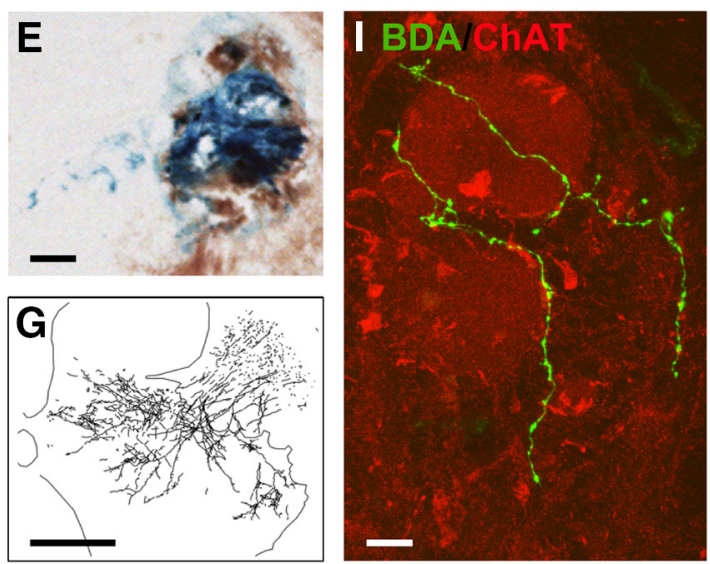

Figure 1. Experimental design and timeline. $\boldsymbol{A}$, Time course of normal map development for the cat RN and motor cortex (M1) represented as a gradient from immature to mature. RN map development precedes that of the M1 map and is more protracted later into adolescent development. The effects of M1 inactivation on RS development were studied in two groups: PW 7 and PW 14. $\boldsymbol{B}$, Representative RN injection sites for BDA (left) and AF488DA (right) from the same coronal section (RN boundary corresponds to the dotted line; left, arrow points to third cranial nerve). Images are merged fluorescence and dark-field micrographs. C, Representative midbrain coronal Nissl-stained sections of RN (dotted line) showing microelectrode tracks and marking lesions (vertical arrows) made during the microstimulation mapping experiments. Third cranial nerve fascicles are present at the ventromedial border of the RN (oblique arrows, $\boldsymbol{C}$. D, E, Nissl-stained section (D) and adjacent section ( $\boldsymbol{E}$ ) stained with Prussian blue. $\boldsymbol{E}$, High magnification of an electrode tract represents where iron was deposited in the tissue with electric current and stained with the Prussian blue reaction. Staining corresponds to the blue-black area. $\boldsymbol{F}$, Representative RST labeling on a single spinal cord section. BDA-stained axons are located in the dorsolateral white matter and throughout the gray matter. $\boldsymbol{G}$, Drawing of labeled RST from multiple sections in the same animal, of which one is shown in $\boldsymbol{F}$. $\boldsymbol{H}$, Schematic summary of the (S (gray/black) and RS (red) pathways to the spinal cord at PW 5. Although the CST projections are bilateral at this age, only the contralateral projections are shown. The forelimb representation in M1 was unilaterally inactivated from PWs 5-7. The side that M1 was inactivated is termed the "inactive side," and the other termed the "active side." I, Representative example of RST axons within a motor pool. BDAlabeled RST axons (green) are present and making contacts with ChAT-labeled motoneurons (red). Scale bars: $\boldsymbol{B}, \boldsymbol{C}, 500 \mu \mathrm{m} ; \boldsymbol{D}, 500$ $\mu \mathrm{m} ; \boldsymbol{E}, 50 \mu \mathrm{m} ; \boldsymbol{F}, \mathbf{G}, 500 \mu \mathrm{m} ; \boldsymbol{I}, 10 \mu \mathrm{m}$. 
pairments are abrogated, and presumably activity returns, within several days (Friel et al., 2012). The RN ipsilateral to the inactivated M1 is often referred to as the "inactivated or inactive M1-side" RN because its RST projections overlap the CST projections from the inactivated M1 (Fig. $1 H$ ). Similarly, the $\mathrm{RN}$ on the side of the noninactivate/active M1 is termed the "active or active M1-side" RN because its RST projections overlap the CST projections from the active M1.

\section{RN motor map development depends on CS activity}

To determine changes in the $\mathrm{RN}$ motor representation, we used microstimulation. We have previously shown that maturation of the motor maps in $\mathrm{RN}$ and $\mathrm{M} 1$ is characterized by progressive increases in the number of sites where microstimulation evokes a response (effective sites) and decreases in current threshold (Chakrabarty and Martin, 2000; Williams et al., 2014). The RN forelimb motor map represents all joints at PW 7, as shown in the $3 \mathrm{D}$ view (Fig. $2 A$, inset shows control map; effective sites are colored spheres) (Williams et al., 2014). The dotted lines indicate the approximate boundary of the RN. That all joints are represented at PW 7 is clear in the caudolateral perspective (C) as well, which also shows the locations of microelectrode tracks where no responses were evoked.

For RN on the side of the inactivated M1 (Fig. $2 A, C$, right column), similar to controls, there are many effective sites along the tracks. By contrast, the active RN (left column), despite being located within the histologically defined RN, had few effective sites. This demonstrates a striking reduction in the size of the motor map in the active RN. We did not observe a systematic difference in $\mathrm{RN}$ size for the active- and inactive M1-side RN on Nissl-stained sections, nor did we note any obvious neuron loss in the active RN. The paucity of effective sites on the active side was not related to the state of the animal because we typically made microelectrode penetrations in alternating blocks on each side with the same electrode. At PW 7 , the percentage of effective sites on the active side was less than the inactive side (Fig. $3 A 1 ; t=3.86, p<0.01$ ) and control $(t=4.36, p<0.02)$, whereas the inactive side was not different from controls $(t=1.53, p>0.26)$.

The maps in Figure 2 also represent the current threshold for evoking movements as the inverse size of the colored spheres marking the effective sites. Not only were there fewer effective sites on the active side but the mean current threshold for evoking the responses was significantly higher than the inactive side (Fig. $3 B 1 ; t=7.74, p<0.001)$ and control $(t=$ $5.11, p<0.001)$. In contrast, mean threshold for the inactive side was significantly lower compared with control (Fig. 3B1; $t=7.97, p<0.0001$ ). These findings show major map impairments in RN on the active side, akin to delayed or arrested development, and suggest precocious map development in RN on the inactive side.

To better represent the effect of CS inactivation on the population of RN sites comprising the motor map development, we constructed frequency distribution histograms of current thresholds at effective sites within the active and inactive sides across all animals (Fig. 4A). Relative to controls (Fig. 4A, dotted line) (Williams et al., 2014), the distribution of active side thresholds is shifted significantly to the right (threshold elevation; dark gray area), whereas the inactive side is significantly shifted to the left (reduced thresholds; Kolmogorov-Smirnoff test: PW 7 control, $n=3$ animals; $n=151$ sites; inactive, $n=4$ animals; $n=168$ sites; active, $n=4$ animals, $n=55$ sites; active-control, $\mathrm{D}=0.30$,

\section{Active Inactive}

\section{A PW 7}

\section{A1}

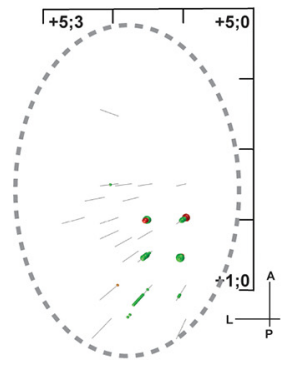

A2

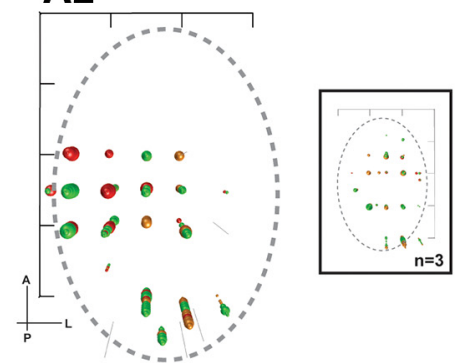

Wrist OElbow Shoulder $\underset{\substack{\mu A \\ 01-20}}{\mathrm{a}}$ 21-40 41-60

\section{B PW 14}

B1
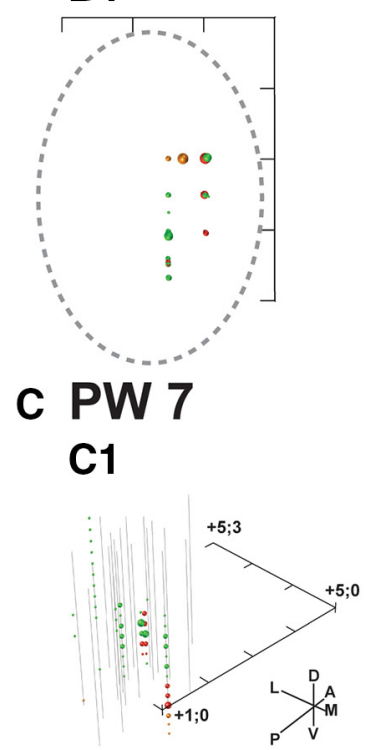

\section{PW 14}

D1

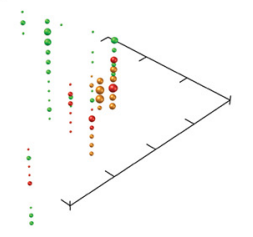

B2
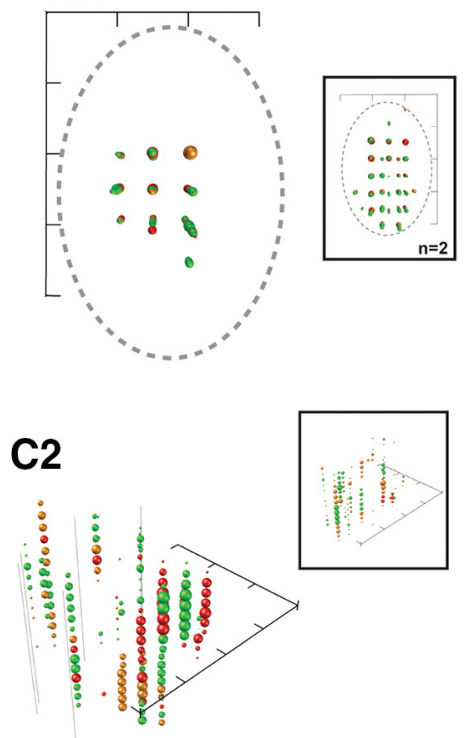

D2

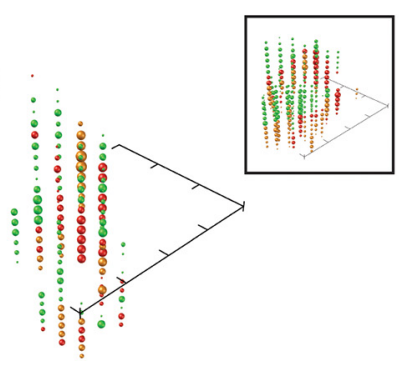

Figure 2. Reconstructed motor maps in the RN. The forelimb representations are plotted in 3D from dorsal (top down; $\boldsymbol{A}, \boldsymbol{B}$ ) and caudolateral $(\boldsymbol{C}, \boldsymbol{D})$ perspectives. $\boldsymbol{A}, \boldsymbol{C}$, Maps are from the PW 7 group. $\boldsymbol{B}, \boldsymbol{D}$, Maps are from the PW 14 group. Insets, Age-matched controls (PW 7, $N=3 ;$ PW 14, $N=2$ 2). Each sphere represents an effective microstimulation site assigned by color for different joint movement responses (green represents wrist; blue represents elbow; orange represents shoulder). Sphere size plots threshold value inversely (largest spheres have the lowest thresholds; $20 \mu \mathrm{A} / \mathrm{bin}$ ). Four representative maps from each side were combined for comparisons: left, active side; right, inactive side. The region within the RN (dotted outline) that was sampled was consistent across animals (axis ticks, $1 \mathrm{~mm}$ ). Ineffective tracks are shown as solid gray lines for the PW 7 group only, to demonstrate adequate sampling within the relatively unresponsive $\mathrm{RN}$ on the active side. Maximal currents: $\boldsymbol{A}, \boldsymbol{C}, 125 \mu \mathrm{A} ; \boldsymbol{B}, \boldsymbol{D}, 100 \mu \mathrm{A}$. 
$p<0.01$; inactive-control, $\mathrm{D}=0.32, p<$ 0.01 ; active-inactive, $\mathrm{D}=0.52, p<0.01$ ).

The distribution of joints represented in $\mathrm{RN}$ on the active side was abnormal at PW 7. The map on the active side had an overrepresentation of wrist sites compared with inactive sides and control (Fig. $5 A ; F=6.58, p<0.03)$. It is interesting to note that typically developing cats have an overrepresentation of the wrist at PW $5-6$, suggesting that the active side map is fixed at the age before CST inactivation. This increase appeared as the reciprocal decrease of shoulder representation in the active side map $(F=6.92, p<0.02$; elbow: not significant). As described further below, this difference did not persist in the older age group. To summarize, the inactive RN at PW 7 shows reduced motor thresholds, whereas the active $\mathrm{RN}$ has both a reduced number of effective sites and elevated motor thresholds. These findings support precocious map development on the inactive side and impaired, possibly arrested, map development on the active side during unilateral M1/CST inactivation.

There are persistent changes in the RN motor map after CS activity returns

We next examined the impact of early CS inactivation on RN motor map development after activity returned. We hypothesize that, if differences in $\mathrm{RN}$ map development between the active and inactive sides at PW 7 were due to the loss of M1 activity, then each would look more like typically developing cats once activity returned. Instead, if differential development of the two RS systems after the M1 activity blockade were determined by changes in the functional organization of the developing CS systems after inactivation (Martin et al., 2009), then differences should persist because, left untreated, CS changes after inactivation are bilateral and permanent.

At PW 14, typically developing cats have a more complete RN motor map and significantly lower current thresholds than at PW 7, but the map is not yet fully mature compared with adult data from our previous study (Williams et al., 2014). The RN map on the inactive side (Fig. 2B2,D2) continues to show a larger number of lower threshold effective sites than the RN on the active side but is less than controls (see below). Whereas there are more effective sites on the active side across all electrode penetrations at this age, the majority have thresholds in the maximal range. The percentage of effective sites was not different between sides (Fig. $3 A 2 ; t=1.64, p>0.16$ ) because there was a regression of the map on the inactive side, with fewer effective sites. Motor thresholds were still lower on the inactive than active side (Fig. $3 B 2 ; t=4.07, p<0.001$ ). In comparison with controls, the active side remained abnormally devel-
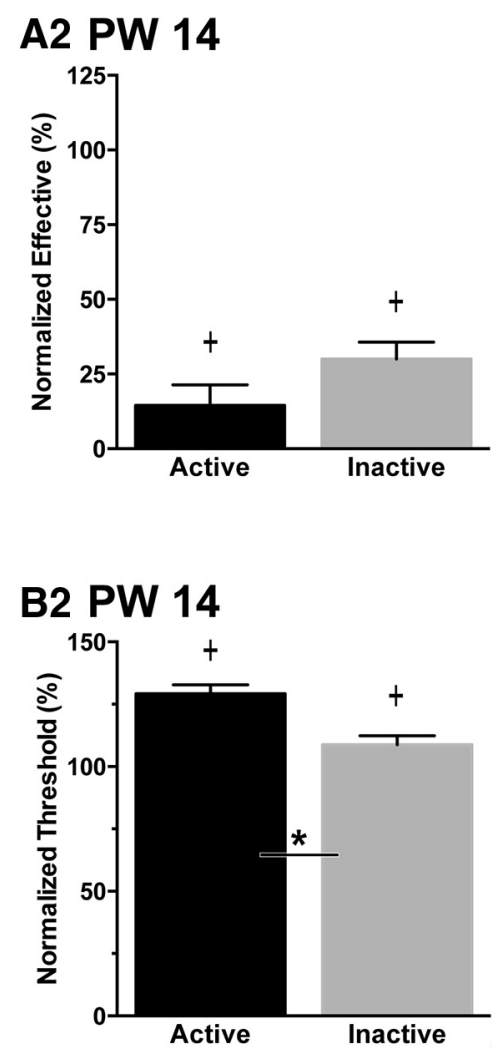

Figure 3. Effective sites and microstimulation current thresholds. $A$, Effective sites in the RN on the same side as the active/ noninfused M1 (left bars) and the RN on the side of the inactivated M1 (right bars) at PW 7 (A1) and PW 14 (A2). B, Same as $\boldsymbol{A}$ but for motor threshold. Plots are normalized to age-matched control values. *Significant difference between sides. ${ }^{+}$Significant difference from age-matched control.

\section{A PW 7}

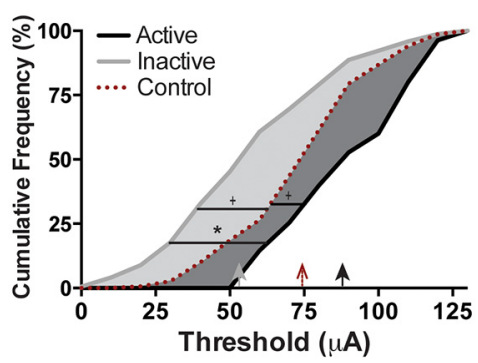

\section{B PW 14}

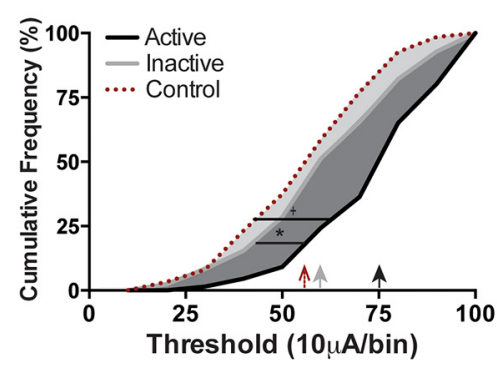

Figure 4. Cumulative distributions of microstimulation-evoked response thresholds. Light gray line indicates inactive RN thresholds. Black lines indicate inactive RN thresholds. Dotted red lines indicate age-matched control thresholds. A, PW 7. B, PW 14. The $x$-axis spread between histograms is present at the $50 \%$ mark of each distribution (arrows). *Significant difference between sides. ${ }^{+}$Significant difference from age-matched control.

oped with a fewer number of effective sites and elevated threshold (effective $t=12.33, p<0.002$; threshold $t=8.31, p<0.001$ ). The augmented development of the RN map on the side of the previously inactivated M1 at PW 7 was not maintained by PW 14 but instead showed a regression toward the controls. The number of effective sites was reduced relative to controls and motor thresholds became slightly elevated above controls (effective $t=12.38$, $p<0.01$; threshold $t=2.39, p<0.02$ ). The results indicate that there was still a disparity in the map between sides and from controls. The active side continued to show abnormal map development, consistent with a failure in map development compared with PW 5-week-old animals (Williams et al., 2014). The 


\section{A PW 7}

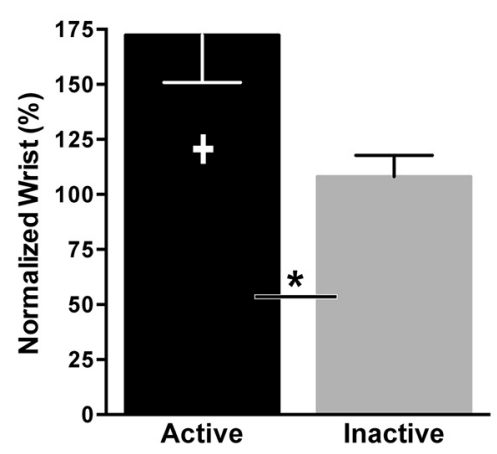

B PW 14

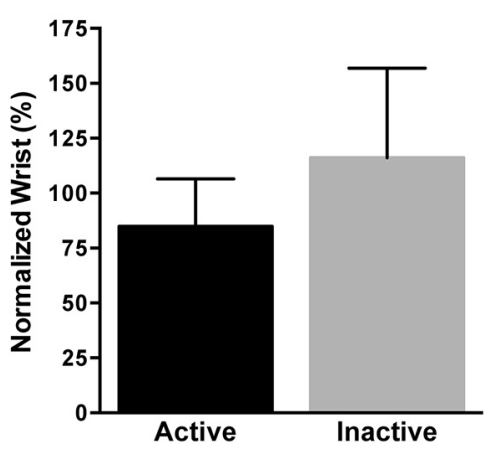

The overall topography of RS projections from each side did not differ qualitatively from the control distribution. Rather, there were differences in the density of projections. As seen in the heatmap representations (Fig. $6 A$ ), at $\mathrm{PW} 7$ the active side had strikingly fewer axons and varicosities than the inactive side (axon $t=3.12, p<0.02$; varicosity $t=3.59, p<$ $0.01)$ as well as reduced axons and varicosities compared with age-matched controls (axon $t=14.29, p<0.001$; varicosity $t=$ $11.15, p<0.001)$. Whereas we expected augmentation in RST projections on the inactive side, considering the changes in the motor map, they were not significantly different from controls (axon $t=$

inactive side failed to maintain precocious development and actually showed a regression.

Across the population of effective sites at PW 14, there was now a surprising rightward shift in the threshold distribution of the RN on the side of the inactivated M1, so that the map was no longer augmented relative to controls (Fig. $4 B$; inactive-control: $\mathrm{D}=0.15, p=0.11$; light gray area). For the RN on the side of the active M1, there was no further change in the distribution; it was still impaired relative to control and from the RN on the side of the inactivated M1 (Fig. $4 B$; active-control: $\mathrm{D}=0.41, p<0.001$; dark gray area). There continued to be a difference between the two sides (active-inactive: $\mathrm{D}=0.30, p<0.01$ ). Interestingly, the active side threshold distribution at PW 14 shifted slightly to the right rather than undergo the strong leftward shift expected for typical development during the same period. The small overrepresentation in the wrist at PW 7 in the active RN was not maintained at PW 14, where there were no differences in joint distributions between sides or with controls (Fig. $5 B ; F=0.29$, $p>0.76$ ). Our findings do not support a simple restoration of the motor map characteristics once M1/CS activity returns. Rather, they are consistent with a persistent effect brought about by changes in CS system reorganization at this age.

\section{RST projections at PW 7 and PW 14 parallel RN motor map changes}

We next determined the changes in RST projections produced by CS inactivation. We traced spinal projections in both age groups and constructed color-coded "heat maps" of the distribution of contralateral RST axons and axon varicosities throughout the gray matter of the cervical enlargement (Fig. 6). Consistent with our previous study (Williams et al., 2014), axon varicosities typically colocalize the synaptic vesicle protein synaptophysin, suggesting that they are presynaptic sites. Two overall considerations steered our anatomical analyses. First, we aimed to determine whether changes in RST development parallel changes in the RN motor map. Here we looked for differences in the overall density of RST projections from the two sides. Second, as previously demonstrated unilateral CS inactivation produces striking changes in CST projections compared with normal development (Friel and Martin, 2005, 2007; Friel et al., 2012). The inactivated CS projects to the contralateral dorsomedial dorsal horn; this is an aberrant territory. The untreated CS, in addition to projecting to the contralateral gray matter like controls, develops an ipsilateral misprojection to the deep dorsal horn and intermediate zone (Salimi et al., 2008). We looked for changes in the density of RST in relation to these CST-projecting territories.

$0.66, p>0.55$; varicosity $t=0.16, p>0.88$ )

The results for the older cohort were surprising. For the active side, there was no obvious compensation after M1 activity returned. The scant distribution of axons and varicosities on the active side compared with inactive was maintained into late adolescence (axon $t=4.46, p<0.007$; varicosity $t=2.15$, $p<0.05$ ). The active side remained poorly developed compared with agematched controls as well, indicating persistence of weak connection strength (axon $t=40.79, p<0.001$; varicosity $t=25.64, p<$ $0.002)$. Also surprising was that the inactive side also had a lower axon density compared with control $(t=5.73, p<0.03)$. Varicosity density on the inactive side was not significantly different from control ( $t=1.22, p>0.35)$. These finding show consistent reductions in $\mathrm{RST}$ projections from the $\mathrm{RN}$ on the active side. Rather than an augmentation of the RST on the inactive side, there was a small axonal reduction.

A separate analysis was performed for RST projections to the forelimb motor pools within lamina IX (Fig. $7 A, B$ ). This is an early-developing RST projection that correlates with development of the RN motor map (Williams et al., 2014). Moreover, this is a target of the RST that is not inherent to the CST in cats. Because this projection is sparser than more dorsal regions, interanimal variability tended to be higher. Comparisons between the two sides showed that axon and varicosity density within the motor pools at PW 7 was weaker on the active side compared with the inactive side (Fig. $7 A$; axon: $t=2.67, p<0.05$; varicosity: $t=$ $3.53, p<0.02)$. Furthermore, the active but not inactive side had a paucity of axons and varicosities relative to controls (active side: axon $t=36.29, p<0.001$; varicosity $t=11.07, p<0.002$; inactive side: axon $t=0.13, p>0.09$; varicosity $t=1.38, p>0.40)$. A similar pattern of RS connection strength between sides, having fewer on the active side, within the motor pool region at PW 7 was also observed at PW 14 (Fig. $7 B$; axon: $t=2.66, p<0.02$; varicosity: $t=2.70, p<0.03)$. Furthermore, the active but not inactive side was much less developed compared with controls (active: axon $t=270.30, p<0.0001$; varicosity $t=33.04, p<$ 0.001 ; inactive: axon $t=2.57, p>0.12$; varicosity $t=0.72, p>$ $0.54)$.

In sum, our findings suggest that the spinal connections of the active side RS were substantially disadvantaged compared with the inactive side at both key time points. This disparity between the two sides was also apparent in lamina IX. In the context of the typically developing RST, the active side was poorly developed early, and this was not overcome. Remarkably, the density of RST terminations from the inactive side 


\section{A PW 7}

A1

Active Inactive
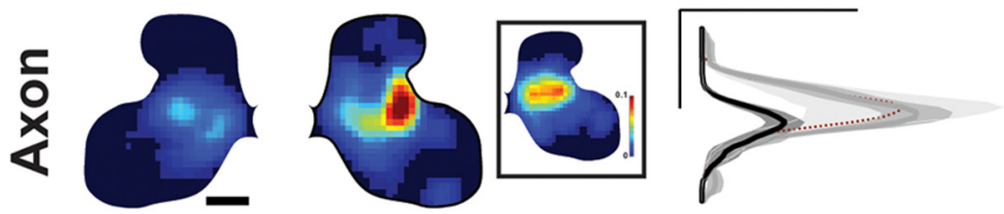

- Active

- Inactive

..... Control
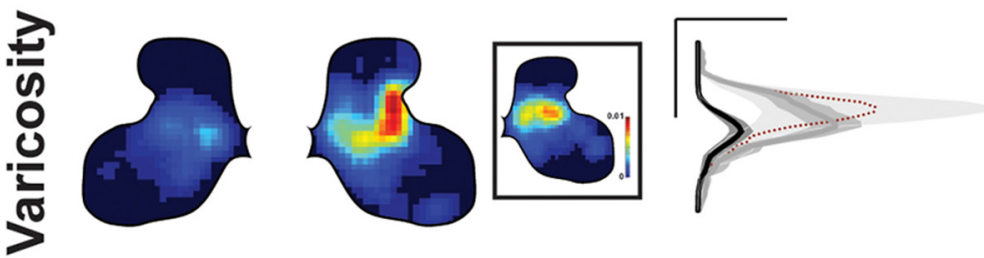

A3
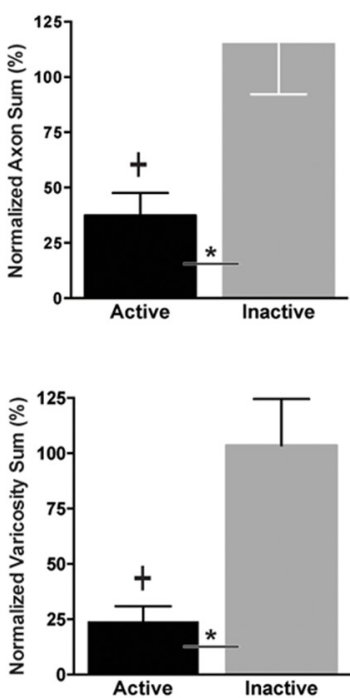

в PW 14

B1

B2

\section{Active Inactive}
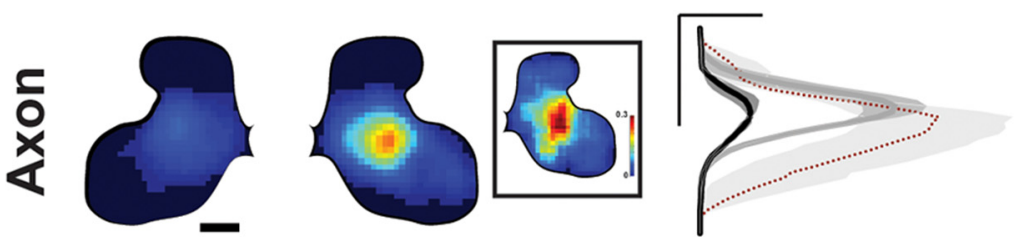

- Active

- Inactiv

..... Control

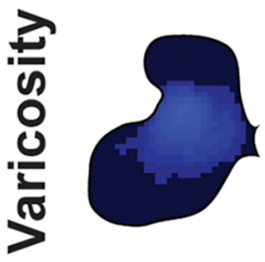

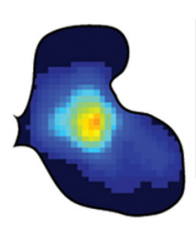

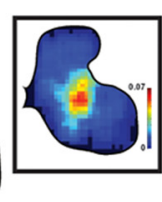

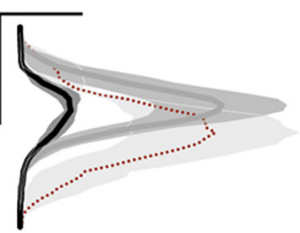

B3
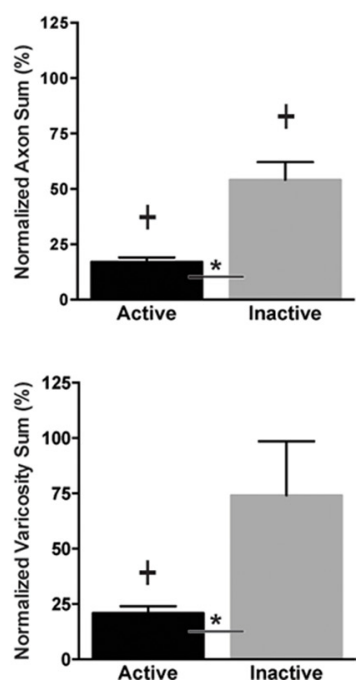

Figure 6. Regional RST axon terminations and varicosities. Each panel represents data for axons (top) and varicosities (bottom). Left panel (1) represents heat maps of regional axon and varicosity density. Color scales for each row are the same to enable comparison. Insets, Control groups. Middle panel (2) represents dorsoventral distribution of axons or varicosities for active side (black line and dark gray area plots \pm SE), inactive side (gray line; dark gray area), and controls (dotted red line and light gray area). Right panel (3) represents axons or varicosities within all gray matter regions,

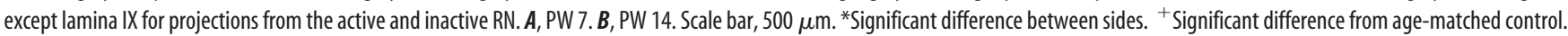

was similar to controls at PW 7 but was subsequently weakened by PW 14, before maturing.

\section{Discussion}

The rubrospinal and corticospinal systems have complementary physiological and anatomical organizations, enabling each to participate in limb control. Reversible inactivation of either system results in unique motor impairments (Martin and Ghez, 1988; Martin et al., 1993). We previously found that there is a complementary temporal pattern of RS and CS codevelopment, with precocious development of the RS enabling it to play a more important role in limb movements very early in postnatal development followed by a reversal of roles later in development as the CS matures (Williams et al., 2014). Now we show a novel mechanism whereby CS activity shapes later RS development, both the RN motor map and RST termination density. Surprisingly, despite manipulating CS activity unilaterally, there were strong consequences for RS development bilaterally. This is reminiscent of the CS, which shows bilateral changes in CST 


\section{A PW 7}

A1

Active Inactive
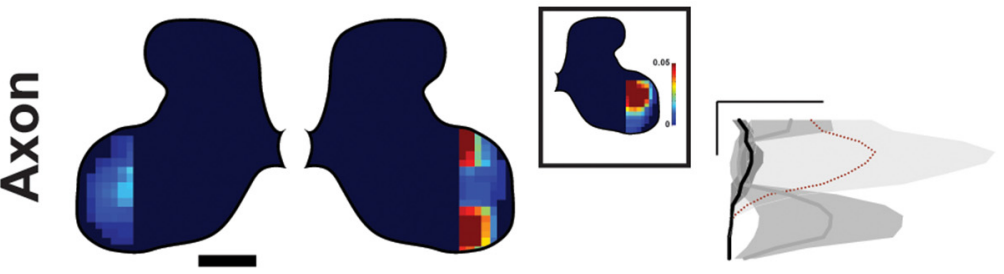

A2

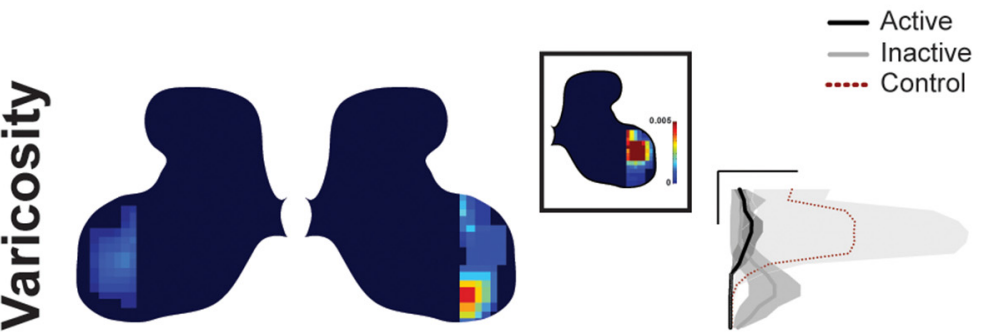

в PW 14

B1

B2
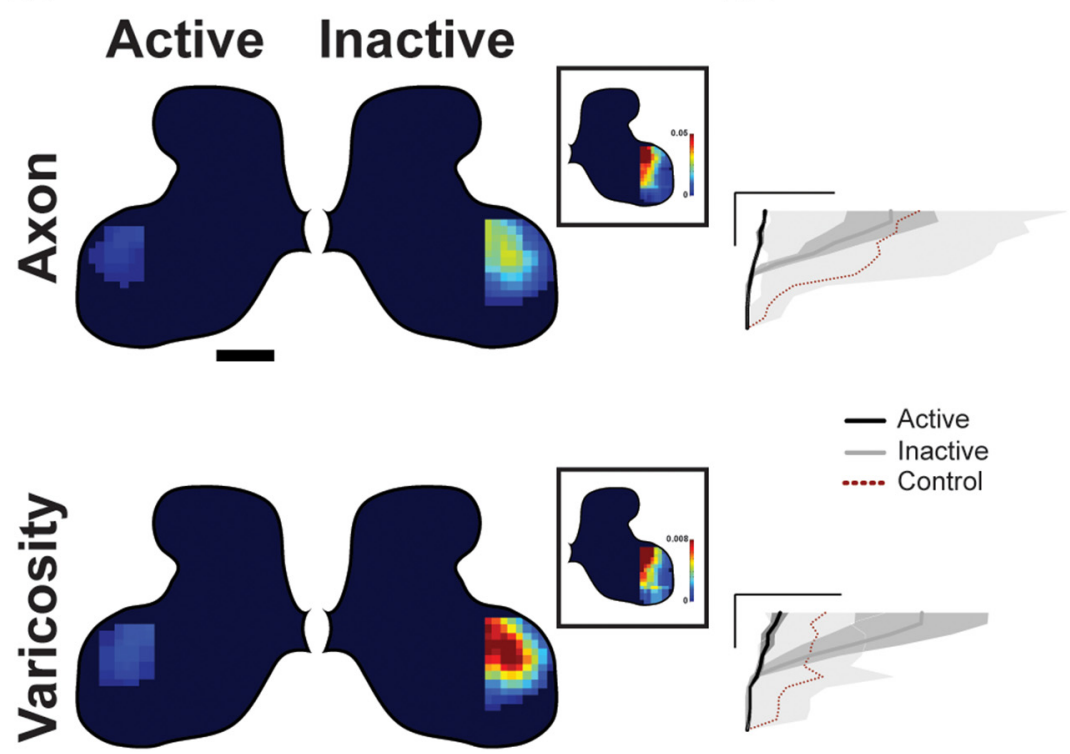

A3
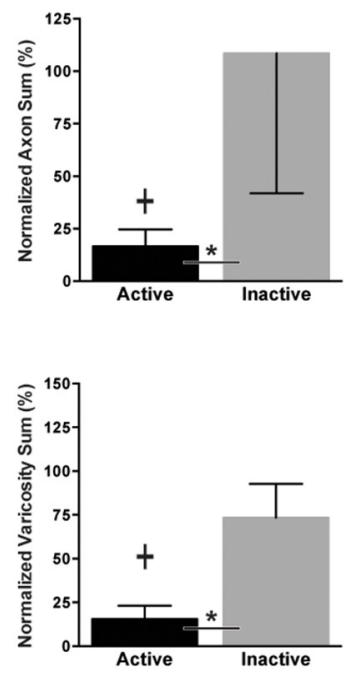

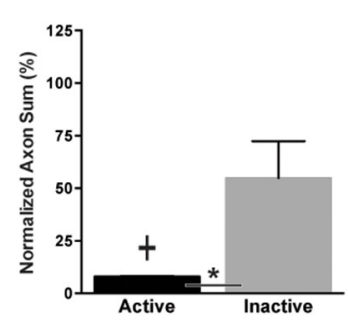

\section{B3}

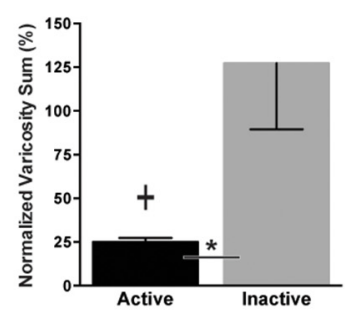

Figure 7. RST projection to the motor pools. Same organization as in Figure 6. A, PW 7 group. B, PW 14 . Scale bar, $500 \mu \mathrm{m} .{ }^{*}$ Significant difference between sides. ${ }^{+}$Significant difference from age-matched control.

spinal with unilateral activity manipulation during development (Friel and Martin, 2007). We conclude that during normal development the RS is under activity-dependent regulation by the CS for establishing the mature $\mathrm{RN}$ motor map and RST projections. In the context of development of the motor systems, with its myriad descending pathways, our findings show how the CS could help establish the balance of control that these two lateral motor systems exert over voluntary limb movements.
Activity-dependent competition with the CST establishes the aberrant pattern of RST spinal connections after unilateral M1 inactivation

The RST projects to the spinal cord before the CST and, in the cat, establishes a mature pattern and density of connections in the intermediate zone from the third week of age; rubromotoneuronal connections begin to develop at 5-7 weeks of age ( $\mathrm{Li}$ and Martin, 2001; Williams et al., 2014). Although still immature, at these early ages the RN motor map represents all forelimb joints. 
This timing gives the RS an early edge over the CS in limb control because the projections of the CST are sparse, relatively unbranched, and have a low percentage of terminals that are competent to release neurotransmitter because only 30\% colocalize synaptophysin (Martin et al., 2004). Further, the motor map does not begin to develop until PW 7 and does not represent all forelimb joints until about PW 13 (Chakrabarty and Martin, 2000), when the apparent dominance of the CS in spinal projections and limb control is established. We used M1 muscimol infusion to inactivate the CS. Muscimol presumably affects all local neurons expressing $\mathrm{GABA}_{\mathrm{A}}$ receptors, including descending projection neurons to brainstem and spinal cord. Thus, it cannot be ruled out that some of the effects of M1 inactivation on the developing RST are mediated indirectly through supraspinal effects. However, it is known that M1 inactivation does not have a significant effect on the laterality of the corticorubral projection; it continues to be a predominantly ipsilateral projection as in naive cats (Martin et al., 1999).

After typical development, the RST and CST contralateral projections overlap in certain areas of the spinal gray matter (Fig. $8 A$ ), including the deep dorsal horn and intermediate zone, and are distinctive in other areas such as the motor pools (McCurdy et al., 1987; Williams et al., 2014). There are no documented ipsilateral RST projections and sparse ipsilateral CST projections (gray). During unilateral CS inactivation, as the CST projections are initially developing (PWs 5-7), the RS on the inactivated side transiently dominates limb control by having a more mature map and axonal projections than normal for this stage of development. At the end of the inactivation period, the inactive CST has an aberrant and highly restricted contralateral projection (Fig. $8 B 1$, light blue, right side) that is balanced by a developing ipsilateral CST misprojection from the active M1 (light gray). Whereas the RST did not expand into the lost contralateral CST territory (Fig. 8B1, right side), it was able to increase projection density within its typical termination space. At PW 7, the ipsilateral CST projection is expanded relative to age-matched controls (Martin et al., 1999), but it is not as dense as in older animals subjected to inactivation (e.g., at PW 14) (Martin, 2012). After activity to M1 returns, and the cortical motor map on the previously inactivated side develops, albeit with an impaired organization (Chakrabarty et al., 2009b), the RST on the side that was inactivated shows a substantial loss of axons, and thus connections (Fig. 8B2, red, right side). By PW 14, the ipsilateral CST misprojection increases in density (Fig. 8B2, gray, right side) (Martin, 2012) and is effective in activating spinal cord neurons throughout the termination area (Chakrabarty and Martin, 2010). We propose that the failure of the RST to compensate anatomically for lost CST connections is due to the development of this aberrant ipsilateral CST misprojections from the active M1. This is consistent with our proposed model of synaptic competition between the RST and ipsilateral CST.

Surprisingly, the RN/RST on the same side as the active M1/ CST (Fig. 8B1,B2, left) lost spinal territory and termination density. This can be explained by an inability of that system to compete with the now dominant, contralateral CST that remained active during development. This bilateral CS is more competitive than normal: It has bilateral spinal projections and provides significant control to both limbs (Martin et al., 2000; Friel et al., 2007; Paixão et al., 2013; Serradj et al., 2014). The active side CS/CST is likely to be more active than normal because it is expected to receive less transcallosal inhibition from the other M1. Further, the cortical motor map on the active side has sub-

\section{A Normal mature}

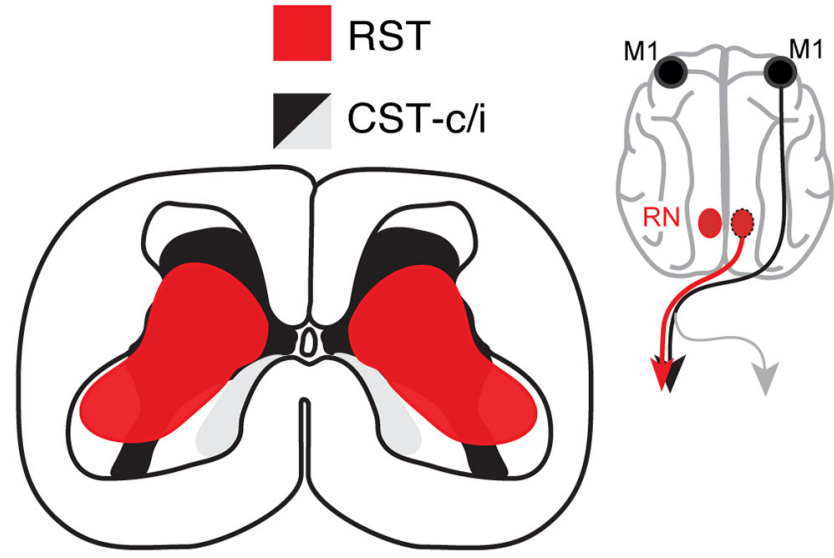

\section{B CS inactivation}

\section{Active side Inactive side

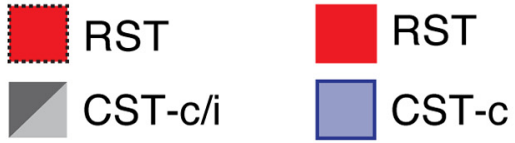

B1 PW 7
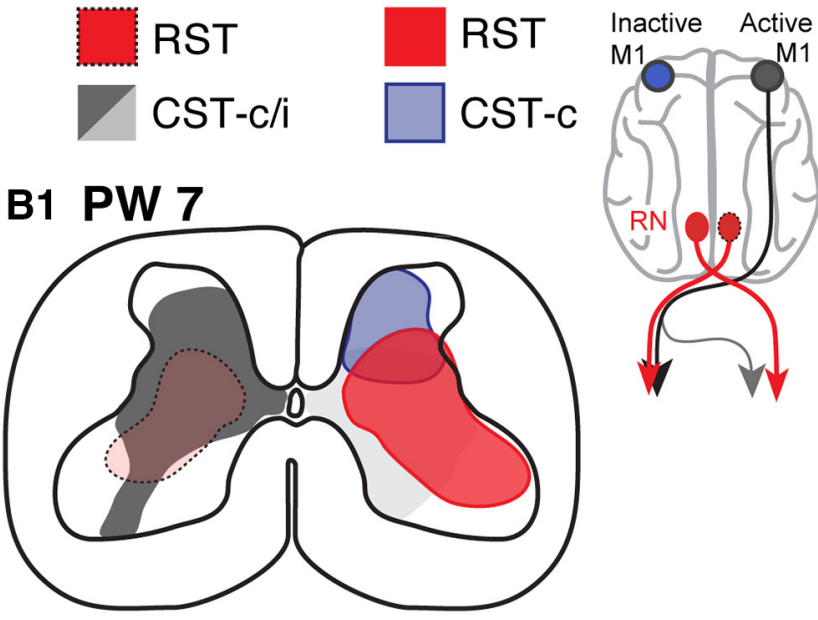

\section{B2 PW 14}

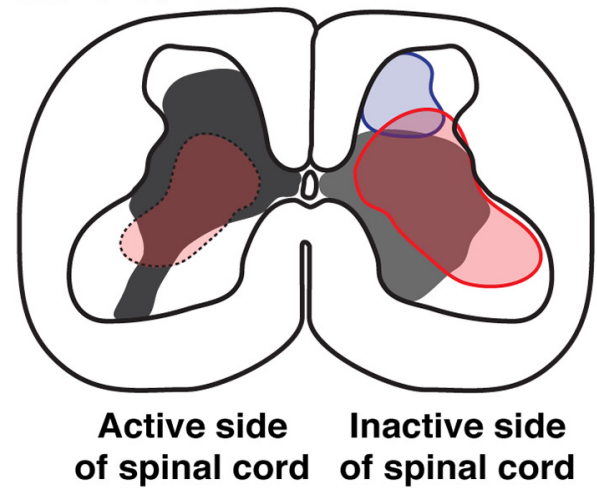

Figure 8. Model for activity-dependent competition between the corticospinal and rubrospinal systems. $\boldsymbol{A}$, Normal mature systems. The mature RST terminations (red) are shown for each RN. There are only contralateral RST projections. The contralateral CST terminations (black) and ipsilateral terminations (light gray) are also shown for M1 in each hemisphere. Inset, Top view of the cat brain with motor cortex (M1) and red nucleus (RN) locations. The RST and CST are shown for one side only. $\boldsymbol{B}$, Sequelae following unilateral CS inactivation between PW 5 and PW 7 , which is a key period of development. The organization of the $C S$ and RS systems at PW 7 at the end of the CS inactivation and at PW 14, 7 weeks after M1 activity returns are shown in $\boldsymbol{B} 1$ and $\boldsymbol{B}$, respectively. The relative intensity of color shading represents axon density. $\boldsymbol{B}$, Left side, Distribution of contralateral projections from $\mathrm{M} 1$ that was active during early development and from the RN from the same side. Right side, Distribution of projections from M1 that was inactivated and from the RN from that side. Note the presence of ipsilateral projections from the active M1. 
stantially more effective sites than the inactive side when mapped between PW 11 and PW 16 (Chakrabarty et al., 2009b). These findings support our hypothesis the developing RS and CS are in competition for spinal synaptic space. This has broad implications for development of the functions of the lateral motor system.

Our results also show a potentially novel mechanism for development of multiple interrelated motor systems, that the RS is shaped by CST activity. This could be an active developmental process, whereby the CST exerts a trophic function on RN development, as it does for spinal cholinergic interneuron development (Chakrabarty et al., 2009a). CST neurons produce a variety of growth factors (Tetzlaff et al., 1994; Giehl, 2001), as well as the morphogens (e.g., sonic hedgehog) (Harwell et al., 2012), that could influence development of rubrospinal neurons (via secretions from the corticorubral projection) as well as in the spinal cord. This finding raises the interesting question of whether the CS coordinates late development of other motor circuits, such as from the deep cerebellar nuclei to RN (Gibson et al., 1987) or the reticulospinal system, through corticoreticular and corticospinal interactions.

\section{After perinatal CS injury, the RS yields to maladaptive CST developmental plasticity limiting its role in motor recovery} Unilateral M1 inactivation models the changes that take place after an incomplete developmental lesion: sparse and ineffective contralateral CST projection from the damaged M1 and bilateral spinal projections from the undamaged side (Eyre et al., 2001). Animals and humans achieve partial recovery of muscle strength and limb control after CS lesions during development (Sanger et al., 2006). The long-term changes we observed in the RS, the bilateral loss of RST projections and map development impairments, are not consistent with the RN and RST mediating partial spontaneous recovery.

We previously considered that development of aberrant ipsilateral CST projections are not maladaptive. After impaired development, reversible inactivation of the ipsilateral M1 in animals with ipsilateral CST misprojections exacerbates movement errors, implying that they contribute adaptively to motor skill (Martin et al., 2000). After unilateral CS lesion in maturity, ipsilateral CST projections from the undamaged side likely contributes importantly to recovery of adaptive locomotion skills (Weidner et al., 2001), especially if the ipsilateral projections are augmented by limb use or electrical stimulation (Brus-Ramer et al., 2007; Maier et al., 2008). However, our present findings require a more nuanced interpretation. Development of ipsilateral misprojections may be adaptive for the CST because it repopulates the denervated side of the spinal cord, and it mediates skill. However, the association between the loss of the RN motor map and RST projections on the active side concurrent with the establishment of a bilateral CST projection from the active M1 reflects plasticity that is maladaptive for RS development.

Rather than codevelop according to the normal rules whereby the contralateral projections of RN and M1 interact to establish balanced projections and limb control, our findings suggest that, after a unilateral developmental injury, the spared/less affected CS dominates the competition. In contrast to normal development, this competition is a winner-take-all match. Bilateral injuries may be less disruptive than unilateral injuries because a bilateral injury affords a more balanced development of the different spared motor systems by "leveling the playing field." Our findings provide mechanistic insights into how the effects of a circumscribed unilateral CS injury, common during human de- velopment, such as cortical or subcortical white matter stroke, can spread to corrupt development of the RS, leaving limb control without a backup control system.

\section{References}

Alisky JM, Swink TD, Tolbert DL (1992) The postnatal spatial and temporal development of corticospinal projections in cats. Exp Brain Res 88:265276. CrossRef Medline

Asanuma H, Sakata H (1967) Functional organization of a cortical efferent system examined with focal depth stimulation in cats. J Neurophysiol 30:35-54

Barrett P, Bateson P (1978) The development of play in cats. Behaviour 66:106-120. CrossRef

Berman AL (1968) The brain stem of the cat. Madison, WI: University of Wisconsin.

Brus-Ramer M, Carmel JB, Chakrabarty S, Martin JH (2007) Electrical stimulation of spared corticospinal axons augments connections with ipsilateral spinal motor circuits after injury. J Neurosci 27:13793-13801. CrossRef Medline

Cahill-Rowley K, Rose J (2014) Etiology of impaired selective motor control: emerging evidence and its implications for research and treatment in cerebral palsy. Dev Med Child Neurol 56:522-528. CrossRef Medline

Chakrabarty S, Martin J (2011b) Postnatal refinement of proprioceptive afferents in the cat cervical spinal cord. Eur J Neurosci 33:1656-1666. CrossRef Medline

Chakrabarty S, Martin JH (2000) Postnatal development of the motor representation in primary motor cortex. J Neurophysiol 84:2582-2594. Medline

Chakrabarty S, Martin JH (2010) Postnatal development of a segmental switch enables corticospinal tract transmission to spinal forelimb motor circuits. J Neurosci 30:2277-2288. CrossRef Medline

Chakrabarty S, Martin JH (2011a) Co-development of proprioceptive afferents and the corticospinal tract within the cervical spinal cord. Eur J Neurosci 34:682-694. CrossRef Medline

Chakrabarty S, Shulman B, Martin JH (2009a) Activity-dependent codevelopment of the corticospinal system and target interneurons in the cervical spinal cord. J Neurosci 29:8816-8827. CrossRef Medline

Chakrabarty S, Friel K, Martin JH (2009b) Activity-dependent plasticity improves M1 motor representation and corticospinal tract connectivity. J Neurophysiol 110:1283-1293. CrossRef Medline

Cheney PD, Fetz EE, Mewes K (1991) Neural mechanisms underlying corticospinal and rubrospinal control of limb movements. Prog Brain Res 87:213-252. CrossRef Medline

Clowry GJ, Davies BM, Upile NS, Gibson CL, Bradley PM (2004) Spinal cord plasticity in response to unilateral inhibition of the rat motor cortex during development: changes to gene expression, muscle afferents and the ipsilateral corticospinal projection. Eur J Neurosci 20:2555-2566. CrossRef Medline

Drew T, Prentice S, Schepens B (2004) Cortical and brainstem control of locomotion. Prog Brain Res 143:251-261. CrossRef Medline

Eyre JA, Taylor JP, Villagra F, Smith M, Miller S (2001) Evidence of activitydependent withdrawal of corticospinal projections during human development. Neurology 57:1543-1554. CrossRef Medline

Eyre JA, Smith M, Dabydeen L, Clowry GJ, Petacchi E, Battini R, Guzzetta A, Cioni G (2007) Is hemiplegic cerebral palsy equivalent to amblyopia of the corticospinal system? Ann Neurol 62:493-503. CrossRef Medline

Fetz EE, Cheney PD, Mewes K, Palmer S (1989) Control of forelimb muscle activity by populations of corticomotoneuronal and rubromotoneuronal cells. Prog Brain Res 80:437-449; discussion 427-430. Medline

Friel KM, Martin JH (2005) Role of sensory-motor cortex activity in postnatal development of corticospinal axon terminals in the cat. J Comp Neurol 485:43-56. CrossRef Medline

Friel KM, Martin JH (2007) Bilateral activity-dependent interactions in the developing corticospinal system. J Neurosci 27:11083-11090. CrossRef Medline

Friel KM, Drew T, Martin JH (2007) Differential activity-dependent development of corticospinal control of movement and final limb position during visuallyguided locomotion. J Neurophysiol 97:3396-3406. CrossRef Medline

Friel KM, Williams PT, Serradj N, Chakrabarty S, Martin JH (2014) Activity-based therapies for repair of the corticospinal system injured during development. Front Neurol 5:229. CrossRef Medline

Friel K, Chakrabarty S, Kuo HC, Martin J (2012) Using motor behavior during an early critical period to restore skilled limb movement after 
damage to the corticospinal system during development. J Neurosci 32: 9265-9276. CrossRef Medline

Gibson AR, Robinson FR, Alam J, Houk JC (1987) Somatotopic alignment between climbing fiber input and nuclear output of the cat intermediate cerebellum. J Comp Neurol 260:362-377. CrossRef Medline

Gibson CL, Arnott GA, Clowry GJ (2000) Plasticity in the rat spinal cord seen in response to lesions to the motor cortex during development but not to lesions in maturity. Exp Neurol 166:422-434. CrossRef Medline

Giehl KM (2001) Trophic dependencies of rodent corticospinal neurons. Rev Neurosci 12:79-94. Medline

Harwell CC, Parker PR, Gee SM, Okada A, McConnell SK, Kreitzer AC, Kriegstein AR (2012) Sonic hedgehog expression in corticofugal projection neurons directs cortical microcircuit formation. Neuron 73:11161126. CrossRef Medline

Kuypers HGJM (1981) Anatomy of the descending pathways. In: Handbook of physiology, neurophysiology, Vol II (Brookhart JM, Mountcastle VB, eds), pp 597-666. Bethesda, MD: American Physiological Society.

Lavoie S, Drew T (2002) Discharge characteristics of neurons in the red nucleus during voluntary gait modifications: a comparison with the motor cortex. J Neurophysiol 88:1791-1814. Medline

Li Q, Martin JH (2000) Postnatal development of differential projections from the caudal and rostral motor cortex subregions. Exp Brain Res 134: 187-198. CrossRef Medline

Li Q, Martin JH (2001) Postnatal development of corticospinal axon terminal morphology in the cat. J Comp Neurol 435:127-141. CrossRef Medline

Maier IC, Baumann K, Thallmair M, Weinmann O, Scholl J, Schwab ME (2008) Constraint-induced movement therapy in the adult rat after unilateral corticospinal tract injury. J Neurosci 28:9386-9403. CrossRef Medline

Martin JH (2012) Systems neurobiology of restorative neurology and future directions for repair of the damaged motor systems. Clin Neurol Neurosurg 114:515-523. CrossRef Medline

Martin JH, Ghez C (1988) Red nucleus and motor cortex: parallel motor systems for the initiation and control of skilled movement. Behav Brain Res 28:217-223. CrossRef Medline

Martin JH, Ghez C (1991) Task-related coding of stimulus and response in cat red nucleus. Exp Brain Res 85:373-388. Medline

Martin JH, Cooper SE, Ghez C (1993) Differential effects of local inactivation within motor cortex and red nucleus on performance of an elbow task in the cat. Exp Brain Res 94:418-428. Medline

Martin JH, Kably B, Hacking A (1999) Activity-dependent development of cortical axon terminations in the spinal cord and brain stem. Exp Brain Res 125:184-199. CrossRef Medline

Martin JH, Donarummo L, Hacking A (2000) Impairments in prehension produced by early postnatal sensorimotor cortex activity blockade. J Neurophysiol 83:895-906. Medline

Martin JH, Choy M, Pullman S, Meng Z (2004) Corticospinal development depends on experience. J Neurosci 24:2122-2132. CrossRef Medline

Martin J, Friel K, Salimi I, Chakrabarty S (2009) Corticospinal development. In: Encyclopedia of neuroscience (Squire L, ed), pp 203-214. Oxford: Academic.

Martin P, Bateson P (1985) The ontogeny of locomotor play behavior in the domestic cat. Anim Behav 33:502-510. CrossRef

McCurdy ML, Hansma DI, Houk JC, Gibson AR (1987) Selective projections from the cat red nucleus to digit motor neurons. J Comp Neurol 265:367-379. CrossRef Medline

Meng Z, Li Q, Martin JH (2004) The transition from development to motor control function in the corticospinal system. J Neurosci 24:605-614. CrossRef Medline

Paixão S, Balijepalli A, Serradj N, Niu J, Luo W, Martin JH, Klein R (2013) EphrinB3/EphA4-mediated guidance of ascending and descending spinal tracts. Neuron 80:1407-1420. CrossRef Medline

Payne BR, Lomber SG (2001) Reconstructing functional systems after lesions of cerebral cortex. Nat Rev Neurosci 2:911-919. CrossRef Medline

Raineteau O, Schwab ME (2001) Plasticity of motor systems after incomplete spinal cord injury. Nat Rev Neurosci 2:263-273. CrossRef Medline

Rexed B (1954) The cytoarchitectonic organization of the spinal cord in the cat. J Comp Neurol 100:297-379. CrossRef Medline

Salimi I, Friel KM, Martin JH (2008) Pyramidal tract stimulation restores normal corticospinal tract connections and visuomotor skill after early postnatal motor cortex activity blockade. J Neurosci 28:7426-7434. CrossRef Medline

Sanger TD, Chen D, Delgado MR, Gaebler-Spira D, Hallett M, Mink JW, Taskforce on Childhood Motor Development (2006) Definition and classification of negative motor signs in childhood. Pediatrics 118:2159_ 2167. CrossRef Medline

Serradj N, Paixão S, Sobocki T, Feinberg M, Klein R, Kullander K, Martin JH (2014) EphA4-mediated ipsilateral corticospinal tract misprojections are necessary for bilateral voluntary movements but not bilateral stereotypic locomotion. J Neurosci 34:5211-5221. CrossRef Medline

Tetzlaff W, Kobayashi NR, Giehl KM, Tsui BJ, Cassar SL, Bedard AM (1994) Response of rubrospinal and corticospinal neurons to injury and neurotrophins. Prog Brain Res 103:271-286. CrossRef Medline

Weidner N, Ner A, Salimi N, Tuszynski MH (2001) Spontaneous corticospinal axonal plasticity and functional recovery after adult central nervous system injury. Proc Natl Acad Sci U S A 98:3513-3518. CrossRef Medline

Williams PT, Kim S, Martin JH (2014) Postnatal maturation of the red nucleus motor map depends on rubrospinal connections with forelimb motor pools. J Neurosci 34:4432-4441. CrossRef Medline 